\title{
Book Selection
}

\author{
Edited by J Crocker
}

CF Daganzo: Logistic Systems Analysis: Third Revised and Enlarged Edition

UD Kumar, J Crocker, J Knezevic and M El-Haram: Reliability, Maintenance and Logistic

Support: A Life Cycle Approach

Y Gabriel, S Fineman and D Sims: Organizing and Organizations: An Introduction

P Bendor-Samuel: Turning Lead into Gold: The Demystification of Outsourcing

\section{Logistic Systems Analysis: Third Revised and Enlarged Edition}

\section{CF Daganzo}

Springer-Verlag, 1999. $x v i+286$ pp. $£ 49.50$.

ISBN: 3540655336

Journal of the Operational Research Society (2002) 53, 1399. doi:10.1057/palgrave.jors. 2601458

This is the third edition of a book that was originally published in 1991. In comparison with the second edition (1996), some minor errors have been corrected, references have been updated and many passages have been rewritten to improve readability. Since this book has been around for awhile, probably many OR academics and practitioners are aware of its existence, although they may not be familiar with its actual contents. This was exactly the position I was in, when I received a copy of this book a few months ago. Since then, I have spent quite some time studying the book, an experience that has been both enjoyable and rewarding.

In this book, the author attempts to analyse logistic systems in an integrated way instead of looking separately at the different activities (transportation, inventory control, etc.), as is common in most existing OR literature. In such an integrated approach it is not always possible (and, according to the author, often unnecessary) to use very detailed models. Relatively simple models, that use as little data as possible but still capture the essence of the different activities, are preferred. The objective is to find the properties of reasonable (instead of 'optimal') solutions. This approach is illustrated by means of a simple example in the first chapter of the book, which gives the reader a very good idea of what is to follow. The second chapter is also introductory in nature, since it mainly deals with explaining and defining logistics cost functions. Then, from Chapter 3 onwards, increasingly complex problems are analysed. These chapters deal subsequently with single-origin-to-single-destination problems, single-origin-to-multiple-destinations problems (with and without transhipments) and multiple-origins-to-multipledestinations problems.
In general, it is not hard to follow the analysis of the models. The reader is expected to have only a minimum of background knowledge. In fact, I believe that basic knowledge of calculus is all that is really required.

An important analysis tool in the book is the Continuous Approximation approach, which can be used when the input data vary slowly in the dimensions (such as time and space). If that is the case, then this approach produces accurate approximations of certain cost functions and, therefore, reasonable solutions. Unfortunately, there does not seem to be an easy, systematic way to check whether the CA approach can be used in a particular case. Apparently, one has to have some experience with this method and to develop intuition on when to use it and when not. This actually touches upon my main point of criticism on this book: it is sometimes impossible for the reader to objectively verify certain claims made by the author. In those cases the reader simply has to trust the author, who undoubtedly has a lot of experience with the methods he describes. Some readers (like myself), who are used to having statements backed up by either rigorous proofs or extensive computational experiments, may get a little intimidated by this.

After all, however, I like this book because the integral and global approach it proposes is so different from what one usually finds in mainstream operational research literature. For this reason, I can strongly recommend it to anyone who is interested in analysing complex logistic systems.

Erasmus University Rotterdam APM Wagelmans

\section{Reliability, Maintenance and Logistic Support: A Life Cycle Approach}

UD Kumar, J Crocker, J Knezevic and M El-Haram

Kluwer Academic Publishers, 2000. xix +490 pp. $£ 94.50$. ISBN: 0412842408

Journal of the Operational Research Society (2002) 53, 1399-1400. doi:10.1057/palgrave.jors.2601459

Every so often a technical book comes along that sticks firmly in the memory. Such books fall into one of two 